\title{
BARGAINING IN THE SHADOW OF THE LAW: A TESTABLE MODEL OF STRATEGIC BEHAVIOR
}

\author{
ROBERT COOTER and STEPHEN MARKS with ROBERT MNOOKIN*
}

\begin{abstract}
$\mathbf{P}$ RETRIAL bargaining may be described as a game played in the shadow of the law. There are two possible outcomes: settlement out of court through bargaining, and trial, which represents a bargaining breakdown. The courts encourage private bargaining but stand ready to step from the shadows and resolve the dispute by coercion if the parties cannot agree. Bargaining is successful from an economic viewpoint if an efficient solution to the dispute is found at little cost. In technical language, a dispute is resolved successfully if a solution is found on the contract curve with little expenditure on search.

The usual approach to bargaining in the legal setting assumes that trial is caused by excessive optimism on the part of plaintiff and defendant. ${ }^{1}$ If both parties are optimistic, then there is no way to split the stakes so that each receives as much as he or she expects to gain from trial. In these circumstances, trial is inevitable.
\end{abstract}

\footnotetext{
* The paper's title is borrowed from Robert N. Mnookin \& Lewis Kornhauser, Bargaining in the Shadow of the Law: The Case of Divorce, 88 Yale L. J. 950 (1979). We received helpful criticism of the paper from the law and economics workshop at the University of Chicago. The ideas in the paper were originally presented at seminars in the economics departments at California Institute of Technology and the University of California at San Diego. The research was funded by a grant from the Center for Law and Economic Study, Columbia University School of Law, whose director is Lewis Kadin.

${ }_{1}$ The theory that trial in civil suits occurs because of optimism is developed in John $P$. Gould, The Economics of Legal Conflicts, 2 J. Legal Stud. 279 (1973); Richard A. Posner, An Economic Approach to Legal Procedure and Judicial Administration, 2 J. Legal Stud. 399 (1974), esp. at 419 n. 29. This model of litigation is expanded in William M. Landes \& Richard A. Posner, Adjudication as a Private Good, 8 J. Legal Stud. 235 (1979). A clear summary of the theory is in Richard A. Posner, Economic Analysis of Law 434-400 (2d ed. 1977) [Hereinafter cited as Economic Analysis]. A similar analysis of the cause of trial in criminal cases is found in William M. Landes, An Economic Analysis of the Courts, $14 \mathrm{~J}$. Law \& Econ. 61 (1971).
}

[Journal of Legal Studies, vol. XI (June 1982)]

(C) 1982 by The University of Chicago. All rights reserved. 0047-2530/82/1102-0011\$01.50 
Our approach is different. In our model, excessive optimism is not the fundamental cause of trials. The fundamental cause is the problem of distribution faced by the players. The problem of distribution is to divide the stakes in dispute. A rational bargainer will make a demand such that the gain from settling on slightly more favorable terms is offset by the increased risk of a breakdown in negotiations. Thus, the optimal bargaining strategy of a litigant balances a larger share of the stakes against a higher probability of trial. There will be a positive risk of trial when strategies are optimal.

A player's strategy is optimal when he maximizes his expected utility. Our assumption that individuals maximize expected utility involves an innovation in game theory as applied to law. In the usual analysis, the players simultaneously maximize utility, and an equilibrium is achieved when everyone knows exactly what everyone else is doing (Nash equilibrium). Uncertainty is eliminated. In our analysis, the players simultaneously maximize expected utility, and an equilibrium is achieved when everyone knows the distribution of strategies pursued by others (Bayesian Nash equilibrium). ${ }^{2}$ Uncertainty persists about individuals but not aggregates. The persistence of uncertainty allows some disputes to end in trial.

Notice that, in equilibrium, the litigants understand the true structure of the game, and their expectations are accurate in the sense that subjective probabilities correspond to objective frequencies. In our model, equilibrium expectations are rational, not biased toward optimism or pessimism. ${ }^{3}$

We wish to make predictions about the relation between observable variables and the frequency of trials in equilibrium. Bargaining is like the stock market in the sense that tangible changes have psychological effects. If the psychological effects overwhelm the tangible changes, then predictions are difficult to make. We shall show that tangible variables dominate psychological effects in the usual case, much the way the substitution effects dominate the income effects of a price change in the usual case. Our theorems about the domination of psychological effects by tangible variables enable us to construct a table of predictions. We shall be able to answer some perplexing questions, such as: (1) Is settlement more likely when transaction costs are low? (2) Is settlement more likely

\footnotetext{
2 The concept of a Bayesian Nash equilibrium was introduced by John Harsanyi, Games with Incomplete Information Played by "Bayesian Players," 41 J. Manage. Sci. 320 (1968), esp. pt. 2.

${ }^{3}$ Our model is consistent with the optimism model in predicting that optimism will lead to a greater probability of trial, but it is not a necessary condition for trial that the threat points sum to a value greater than the stakes.
} 
when bargaining is risky? (3) Is settlement more likely when the cooperative surplus is large?

Most of our predictions are consistent with the predictions derived from the optimism model, but we ground the predictions in a more fundamental account of bargaining. A more fundamental account of bargaining offers a different perspective on a variety of legal issues as well as a few different predictions. We shall illustrate the change in perspective by analyzing externalities and legal institutions for reallocating the payoffs from trial.

Part I describes the framework of the model. Part II discusses the domination of psychological effects by tangible variables, which is the basis for comparative statics. Part III explains the table of predictions, and Part IV applies the predictions to externalities and rules for reallocating payoffs from trial. There is little mathematics in the text. The mathematical reader can refer to the Appendix for a brief presentation of our model, or to a companion paper on file with this Journal which develops the mathematics at length. ${ }^{4}$

\section{Framework: Optimization And Equilibrium}

In order to develop the framework, we must characterize the features of bargaining games which distinguish them from other types of games. A zero-sum game is a game in which total winnings minus total losses equals zero. ${ }^{5}$ It is a game of pure redistribution because nothing is created or destroyed. Poker is an example. By contrast, a coordination game is a game in which the players have the same goal. ${ }^{6}$ For example, if a phone conversation is cut off, then the callers face a coordination problem. The connection cannot be restored unless someone dials, but the call will not go through if both dial at once. The players win or lose as a team, and winning is productive, so coordination games are games of pure production.

A bargaining game involves distribution and production. ${ }^{7}$ Typically, there is something to be divided called the stakes. For example, one person may have a car to sell, and another may have money to spend. The stakes are the money and the car. If the players can agree on how to

4 Robert Cooter \& Stephen Marks, Bargaining with Rational Expectations Applied to Law: A Testable Model of Strategic Behavior (1981) (unpublished manuscript on file with J. Legal Stud.).

5 Zero-sum games were first explored in the pioneering book by John von Neumann \& Oskar Morgenstern, Theory of Games and Economic Behavior (1944).

${ }^{6}$ Coordination games are described in Thomas C. Schelling, Strategy of Conflict (1960).

7 A definition of bargaining games and a discussion of solution concepts is in $\mathrm{R}$. Duncan Luce \& Howard Raiffa, Games and Decisions ch. 6 (1957). 
divide the stakes, for instance, if they can agree on a price for the car, then both of them will benefit. The surplus is the joint benefits from cooperation, such as the gains from trading the car for money. If the players cannot agree on how to divide the stakes, then the surplus will be lost. In brief, bargaining games are games in which production is contingent on agreement about distribution.

The fundamental obstacle to cooperation is the absence of an authoritative rule for dividing the stakes. It is up to the players to find a division of the stakes acceptable to both of them. Strategy consists in trying to maneuver an opponent into accepting an unfavorable distribution. The objective of a skillful bargainer is to convince others that he intends to act in such a way that it is in their best interest to do what is in his best interest. Such a bargainer transmits information and makes side payments in order to maneuver his opponents into a position where their perceived self-interest compels them to do what is to his advantage. Inefficient outcomes occur when the players miscalculate, for instance, I think that your sincere threat is a bluff.

Bargaining in the shadow of the law achieves a close fit to our abstract characterization of bargaining games. The players are usually well defined, consisting of a plaintiff and defendant in many cases. The stakes are also well defined, such as the cost of an accident, the damage from nonperformance on a contract, the property accumulated in a marriage, the estate of the deceased, the assets of a bankrupt company. In pretrial negotiations, everyone has an interest in avoiding a trial. The surplus from cooperation is usually obvious, for example, legal fees, cost of delaying resolution of the dispute, waste from a judicial outcome off the contract curve. The plaintiff and defendant have an incentive to avoid trial, but they have a disagreement over how to divide the stakes. There is a problem of efficiency and also one of distribution.

A legal dispute enters the public record when a complaint is filed. A trial date is often set after the complaint is filed which puts a time limit on bargaining. The simplest characterization of the bargaining process is a sequence of offers and counteroffers for dividing the stakes. A settlement is reached if the plaintiff's demand in some round of negotiations does not exceed the defendant's offer. Bargaining terminates and a trial begins if the trial date is reached before a settlement occurs.

In summary, we characterize bargaining in the shadow of the law as a game with the following characteristics: (1) There is a dispute between two players, the defendant and plaintiff, over how to divide the stakes. (2) Bargaining consists in an exchange of demands and offers for dividing the stakes. (3) Settlement occurs if the plaintiff's demand does not exceed the defendant's offer. (4) Trial occurs if a settlement is not reached before the 
trial date. (5) The outcome of a trial is the destruction of part of the stakes (the surplus) and distribution of the remainder.

\section{Optimization}

We have described bargaining in the shadow of the law as a game. Our next task is to characterize the behavior of the players. Each player must choose a bargaining strategy. We can reduce the choice of strategy to its simplest elements by imagining that the plaintiff writes down her final demand, seals it in an envelope, and mails it to the defendant. At the same time, the defendant writes down his final offer, seals it in an envelope, and mails it to the plaintiff. The envelopes are delivered just before the trial is scheduled to begin. If the offer is at least as great as the demand, a settlement occurs. If the demand is greater than the offer, then a trial occurs. The mailing of the envelopes is a device for portraying the uncertainty of each player concerning his opponent's strategy.

This example can be clarified by using some notation to describe how the plaintiff would compute her optimal final demand. Let the stakes be $\$ 100,000$ and let $x$ be the plaintiff's share of the stakes, where $x$ is denominated in hundreds of thousands of dollars. Thus a settlement will occur if the plaintiff demands $x$ for herself and the defendant demands no more than $1-x$ for himself. Let $P(1-x)$ be the probability that the defendant demands no more than $1-x$. Thus the probability of settlement is $P$ and the probability of trial is $1-P$. Let the plaintiff's payoff from trial be $T$. The problem faced by the plaintiff can be written ${ }^{8}$

$$
\max _{x} P(1-x) x+\{[1-P(1-x)]\} T .
$$

This mathematical problem can be solved intuitively. Suppose that the plaintiff is contemplating whether $x$ is her optimal demand. If she increases her demand by $\$ 1.00$, then she stands to gain $\$ 1.00$ with probability $P(1-x)$. However, increasing her demand by $\$ 1.00$ will increase the probability of a trial by the marginal value of $P(1-x)$, denoted $p$. If a trial occurs, then she will lose the difference between her payoff from settlement $x$ and her payoff from trial $T$. Thus the risk of loss from demanding more is $(x-T) p$. At the optimum, the probable gain is exactly offset by the risk of loss: $0=-(x-T) p+\$ 1 P$. The plaintiff's optimal demand is the value of $x$ which satisfies this equality. The same kind of computation is made to find the defendant's optimal demand.

\footnotetext{
${ }^{8}$ For simplicity, we have assumed that the plaintiff is an expected income maximizer in this example. This is equivalent to assuming risk neutrality. In general, all our results hold for both risk-neutral and risk-averse players.
} 
In this example, each player makes one final offer. Real bargaining is a sequence of offers and counteroffers, not a single pair of offers. Consider a more complex example from family law. A divorcing couple without children disagree about how to divide the value of a house. If the spouses can agree on division of the stakes (the house), then they can settle the dispute without lawyers or a trial, and they can arrange for the house to go to the spouse who values it the most. In the pretrial period, the spouses exchange offers and counteroffers. As the trial date for the divorce approaches, both make concessions. Neither knows how much the other will concede. Each decides how much to concede by trading off a larger share of the value of the house against a higher probability of trial. If the concession rates are fast enough, then a settlement occurs, but otherwise there is a trial.

Two possible sequences of bargaining between husband and wife are depicted in Figure 1. If the husband concedes quickly, then a settlement is reached at the time $t^{*}$. If the husband concedes slowly, then the wife's demand exceeds the husband's offer when the trial date $T$ arrives, so the dispute is resolved by trial.

We described the optimal offer in the simple example by an equation. Direct computation of the optimal sequence of offers in the complex problem involves a sequence of equations (dynamic program). In its most general form, the sequence of equations turns out to be mathematically intractable. There is a device which can be used to reduce the complex problem to a form which is mathematically identical with the simple problem. In Figure 1 the husband's strategy which results in trial can be described as harder than the strategy which results in settlement. The reduction of the complex problem to simple form involves developing the concept of hardness as applied to strategies.

A rational bargainer forms a plan for making offers in each round of negotiations. He will probably want to revise the plan according to the way bargaining goes in the early rounds. We can imagine that a rational bargainer anticipates the possible moves of opponents and constructs a complete contingency plan before the first round of negotiations. A contingency plan for making demands will be called a bargaining strategy. One bargaining strategy is harder than another by definition if a player following the first strategy demands at least as much as he would if he were following the second strategy in every round of negotiations, regardless of the contingency. ${ }^{9}$ Graphically, one strategy is harder than another if the offers in the first strategy lie entirely below the offers in the second strategy, as in Figure 1.

${ }^{9}$ A definition of the hardness relation between strategies is in the Appendix. 


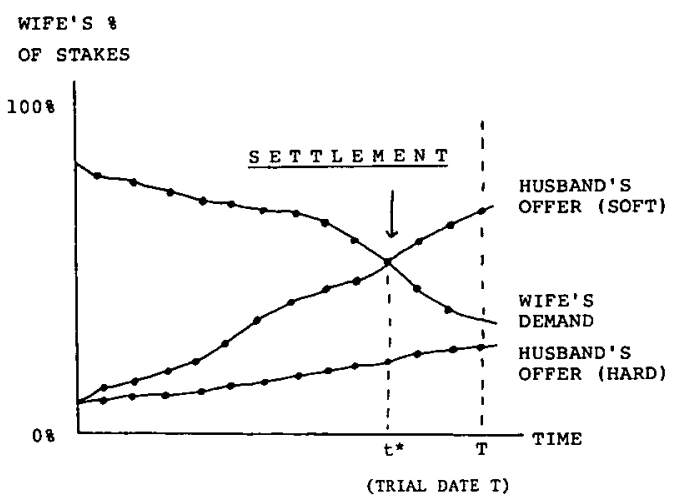

Figure 1

Choosing the strategy of optimal hardness is almost identical mathematically with choosing the optimal final demand. If a player adopts a hard strategy, then he receives a larger share of the stakes in the event of settlement. But a harder strategy is less likely to result in settlement. If the pair of strategies chosen by the players is too hard, then the dispute will be resolved by trial. Thus a player finds his optimal strategy by trading off a larger share of the stakes against a higher probability of trial. There is no substantial change in the mathematical formulation of the choice problem, which we discussed above, except that the choice variable $x$ is interpreted as an index of the hardness of the strategy. (See Appendix for details.) This approach makes the dynamic programming problem mathematically tractable.

\section{Expectations}

We described how players find the strategy which maximizes expected payoffs, assuming that each player has expectations (denoted $P$ ) about what his opponent will do. Our next task is to explain how these expectations are formed. There are various economic models for the formation of expectations, one of which is called rational expectations ${ }^{10}$ This phrase means that expectations contain no systematic bias, that is, the subjective expectations correspond to objective frequencies of the random event. We can characterize rational expectations in our model by explaining the source of uncertainty. Each player in our model has observable and unob-

10 The idea that expectations about macroeconomics should be rational has been developed into an elaborate theory. The first paper was John F. Muth, Rational Expectations and the Theory of Price Movements, 29 Econometrica 315 (1961). 
servable traits. Players with the same observable traits, but different unobservable traits, will pursue different strategies. However, the expectations which a player has about his opponent are formed on the basis of the observable traits alone. Consequently, each player remains in doubt about what his opponent will do. Subjective expectations correspond to objective frequencies when a player expects his opponent to act in a way that corresponds to the actual randomness of the class of players who have the same observable traits as his opponent."

For example, there are many divorces each year which require dividing wealth and income. Each spouse will adopt a bargaining strategy which we assume can be characterized on a scale of hardness. The objective distribution is the actual frequency with which spouses with similar observable traits adopt strategies ranging over the scale of hardness. If the subjective expectations correspond to the objective frequency, then the spouses' expectations are rational.

What is to count as an observable trait? There is much latitude in the model for answering this question. Our ultimate interest is in predicting the way changes in variables observable to policymakers affect the ability of parties to settle out of court. From our perspective, the important observable variables are the ones which have explanatory power in an econometric model.

In this paper we shall stress the assumption of rational expectations, although many of our conclusions remain true if we introduce biased expectations. There is a sense in which rational expectations are more fundamental than biased expectations. If expectations of decision makers are biased, then they will be surprised by the consequences of their choices. If they are surprised, then they will revise their expectations. If their expectations are revised, then the system is not in equilibrium. The rational-expectations model is fundamental because it is intimately linked to the concept of equilibrium, as we shall now show in greater detail.

\section{Equilibrium}

Expectations will be rational if there is a learning process by which bias is corrected. There is a mechanism for learning in the legal setting. In our divorce example, the spouses might seek legal counsel. The lawyers would be experienced with such bargaining situations. It is easy to see how bias would be eliminated from a lawyer's expectations. A lawyer expects a particular strategy on the part of his client to result in noncoop-

\footnotetext{
1 Strictly, we assume that subjective means and variances equal objective means and variances in equilibrium. See Cooter \& Marks, supra note 4.
} 
eration a certain proportion of the time. If his expectations are disappointed, then he will revise them repeatedly until they are accurate. For example, if the husband adopts the conciliatory strategy of demanding only 20 percent of the market value of the house, and the lawyer expects this strategy to produce cooperation in every case but the wife rejects the offer, then the lawyer will have different expectations the next time a similar case occurs. ${ }^{12}$

The learning process which we have described will result in revision of the subjective probabilities until they correspond to objective frequencies. The process will cease when expectations are rational. Thus the equilibrium of the game is a situation in which subjective probabilities correspond to objective frequencies. The equilibrium can be called a Bayesian Nash equilibrium. ${ }^{13}$ It is Bayesian in the sense that each player's optimal strategy is derived from a subjective probability distribution over his opponent's move, and it is Nash in the sense that no one cares to revise his strategy given the strategies of others.

We could modify the definition of equilibrium to allow for biased expectations. For instance, it is possible that litigants are biased toward optimism. Such bias might arise because of a natural impulse toward hope, or because lawyers earn more money by encouraging litigation. To incorporate bias into the model, we would define equilibrium as a condition in which objective frequencies differ from subjective expectations by the postulated amount of bias. A study of optimistic expectations can therefore flow from the rational-expectations model, which is more fundamental because it is the starting place from which to proceed to special cases of bias.

Let us summarize our bargaining model. Bargaining occurs in a context of uncertainty about how opponents will react to offers and counteroffers. The basic approach in economics to choice under uncertainty involves a two-step process: first, form your best expectations about the likelihood of each possible outcome from acting; and, second, calculate your optimal move. The two-step process is called expected utility maximization with Bayesian probabilities. The fundamental problem in game theory is that one player's expectations about another's move depend on the other player's expectations about the first player's move. How can the two-step process be applied simultaneously by everyone? The paradox is resolved

\footnotetext{
12 We assume there is no principal-agent problem, that is, the lawyer's incentives are the same as his client's.

${ }^{13}$ In Harsanyi, supra note 2, there is a different concept of rational expectations. Harsanyi assumes that players follow mixed strategies, but in our own model the strategies are pure.
} 
by specifying expectations in the first step which are confirmed in the second step. Rational expectations have this characteristic because the subjective expectations correspond to objective frequencies.

\section{Basis for Comparative Statics}

As in the stock market, tangible changes have psychological effects upon bargaining. ${ }^{14}$ In order to enable us to make predictions, our model must tie expectations to tangible variables which can be observed. This section explains the link between tangible and psychological variables in our model.

We shall illustrate the link with our divorce example. If the husband acquires a pressing debt, then he will want a quick settlement. His direct response is to make a more generous offer. If the wife knows that her husband has acquired a pressing debt, then she will expect him to make a more generous offer, so she may demand a larger share of the stakes. She responds to the expected revision in her husband's strategy, which in turn is a response to the new debt, so we call her response "indirect." Likewise, the husband may revise his strategy in anticipation of his wife's revision, and so on. If the bargaining game is stable, then the reverberation of indirect responses will eventually peter out and a new equilibrium will result.

The distinction between the direct and indirect responses can be explained in terms of expected utility theory. Bargainers maximize the sum of the utility of each possible payoff weighted by its probability. The direct response is a revision in the optimal strategy that occurs because the utility terms shift, without any change in the probabilities. The indirect responses are revisions in the optimal strategy that occur because the probabilities change, without any change in the utilities. ${ }^{15}$

Revisions in bargaining strategy will change the probability of resolving the dispute by settlement out of court. It turns out that these changes are easy to predict if the effects of tangible variables are not swamped by psychological effects, that is, if the direct effect dominates indirect effects. By definition, the direct effect dominates indirect effects if the

\footnotetext{
14 Joke: A stockbroker died and found himself at the gate to heaven. Saint Peter said, "You may come in, but the area reserved for brokers is crowded." Our hero went to the designated piazza, which was indeed crowded with brokers, climbed the statue in its center, and shouted, "Oil has been discovered in hell." Brokers stampeded from the piazza. Our hero climbed down from the statue and fell in behind them. As he ran through the gate to heaven, Saint Peter, who had observed everything, called to him, "Why are you running with them?" Our hero replied, "They may be on to something."

15 See the Appendix for a mathematical account of the distinction.
} 
direction of the change in probability of settlement is the same as the direction of the change attributed to the direct effect alone.

We can illustrate the domination of direct effects by returning to our divorce example. Recall that the husband acquired a pressing debt and his direct response was to make a more generous offer to settle the dispute. The direction of his direct response can be computed a priori from economic theory. If the husband makes a more generous offer, then settlement is more likely ceteris paribus. A cascade of indirect responses follows. The wife's indirect response is to increase her demand. This may cause the husband to increase his offer further in order to avoid trial. The wife may increase her demand still further. This chain of indirect responses finally peters out. If settlement is still more likely after considering the indirect effects, we say the direct effect dominates the indirect effects.

The analogy with price theory is very close. The effect of a price increase on demand is predictable a priori from economic theory, provided that the income effect is small or has the right sign. Similarly, the effect of a shift in an observable variable on the probability of settlement is predictable a priori from economic theory, provided that the indirect effects are small or have the right sign.

In price theory, there is a long history of estimating income effects. The econometric facts establish that income effects are small or have the same sign as substitution effects in the usual case. This result is not surprising. If income effects dominate substitution effects, then the demand curve is backward bending, which leads to a disorderly reversal in demand as price increases. Common sense suggests that these disorderly reversals are rare.

We do not have a history of econometric estimation of indirect effects in bargaining, but there is reason to expect that econometric studies will establish that the direct effect dominates indirect effects. The reason is the same as for price theory: if indirect effects dominate the direct effect, then continuous variation in parameters leads to disorderly reversals in the probability of settlement.

It is easy to illustrate this claim. Suppose that a change in an observable variable increases the threat value of one player with no change in the stakes. A player demands more when his threat value increases, so the direct effect makes settlement less likely. Assume that this is an unusual case, analogous to a backward-bending supply curve, in which the indirect effects dominate the direct effect. We are assuming that settlement becomes more likely as a player's threat value increases. If we continue increasing one player's threat value, a point will eventually be reached 
where the sum of the threat values of the two players is at least as great as the stakes, in which case settlement is impossible. Consequently, the probability of settlement increases as the threat value increases and then drops precipitously to zero. This argument illustrates our claim that domination by indirect effects leads to disorderly reversals in the probability of settlement caused by continuous alteration of parameters. ${ }^{16}$

It is possible to say something more about these problematic bargaining situations. Let us return to our divorce example. Recall that the wife observed her husband's new debts and expected him to adopt a softer strategy. In technical terms, the wife's subjective probability distribution over her husband's offer shifted to the right. For purposes of analysis we can decompose the shift of the distribution into two segments: the shift of the mean and the shift of the variance, as depicted in Figure 2.

The change in the wife's expectations will cause her to revise her optimal strategy. The revision in the wife's optimal strategy can be divided into two parts corresponding to the decomposition of the shift of expectations, namely, the revision due to the change in the mean and the revision due to the change in the variance. It is possible to prove that the direct effect dominates the indirect effect of the shift in mean expectations. Thus it is clear that the problematic cases are ones in which the change in an observable variable affects the variance in the expectations.

Our divorce example can be used to illustrate a potentially problematic case. The husband acquired a pressing debt which made him eager to settle. Suppose that he acquired the debt because he gambled on the horses. Further, suppose that there is a lot of variance in the behavior of gamblers when they acquire debts, for instance, some take wild risks, while others turn conservative until solvency is restored. It is possible to show that the increase in the variance of strategies will increase the probability of a breakdown in bargaining. ${ }^{17}$ Bargaining is more likely to break down because miscalculation of an opponent's behavior is more likely. Thus the direct effect of the debt is to increase the probability of settlement by making the husband's mean offer more generous, but the indirect effect is to decrease the probability of settlement by increasing the variance in the husband's offer.

We stated that an increase in the objective variance in bargaining

\footnotetext{
${ }^{16}$ Nevertheless, the analogue to Giffens paradox is not unknown. For example, suppose the rule of law for a class of cases becomes much clearer, so that the variance in court decisions becomes small. Most observers believe that trials will become infrequent as a consequence. The reduction in variance will increase the certain monetary equivalent of trial for risk-averse litigants. Thus the threat points (certain monetary equivalent of trial) will probably increase, and, paradoxically, trial will become less likely.

17 The proof is in Cooter \& Marks, supra note 4.
} 


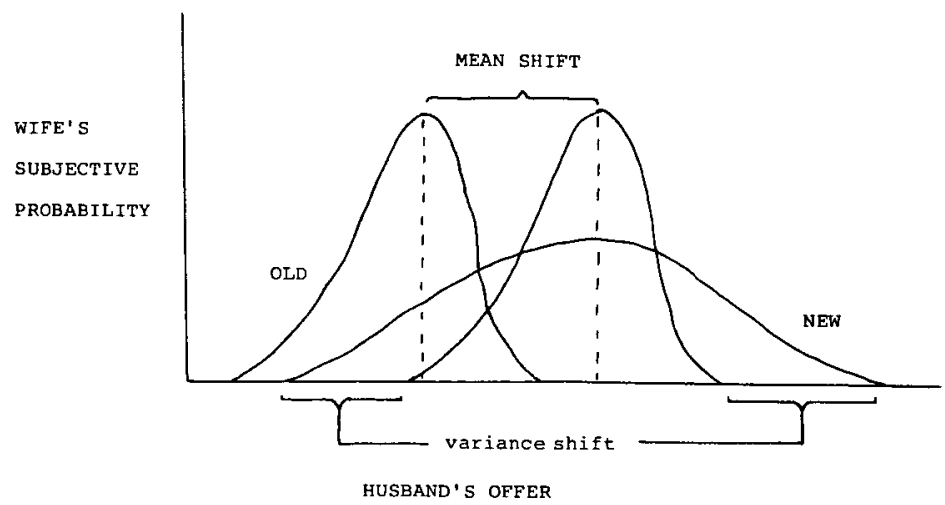

Figure 2

strategies decreases the probability of a settlement. This amounts to the proposition that settlement will be more difficult among strangers because their lack of familiarity with each other increases the likelihood of a miscalculation. Thus, the effect of a change in an observable variable will be unpredictable when the direction of the direct effect on the probability of settlement is the same as the direction of the change in the variance of bargaining strategies, such as when the direct effect causes the probability of settlement to increase, and when the variance in strategies also increases.

\section{Table of Predictions}

We wish to predict how changes in observable variables influence the split between settlement and trial. It is easy to explain the logic of prediction in our model. A player computes his optimal demand by balancing the gain from settling on more favorable terms against the risk of trial. Many observable variables directly influence this computation. An increase in the value of trial (threat value) will make trial more attractive, and the player will demand more. An increase in the value of settlement will make trial less attractive, and the player will demand less. The direct effect of demanding more is that trial is more likely; the direct effect of demanding less is that trial is less likely. In the usual case where direct effects dominate indirect effects, the sign of the change in demand will be the same as the sign of the change in the probability of trial. Thus we make our predictions by computing the direct effect of changes in observable variables upon the demands of the players.

Some predictions are reported in Table 1 . We shall not derive these 
TABLE 1

PREDICTIONS

\begin{tabular}{lc}
\hline \hline Parameter Change & Probability of Settlement \\
\hline P1. Urgency of resolution & $\begin{array}{l}\text { Increases } \\
\text { Decreases }\end{array}$ \\
P2. Improved value of trial (higher certain monetary & \\
equivalent of trial) for one litigant & Increases \\
P3. Increase in transaction costs of negotiating & Increases \\
P4. Increase in transaction costs of trial & Decreases \\
P5. Increase in earnings per period contingent on no & Desolution of dispute \\
P6. Increase in spitefulness toward opponent & Decreases \\
P7. Less risk aversion & Increases \\
P8. Increase in familiarity of opponents (less uncer- & \\
\hline tainty) & \\
\hline
\end{tabular}

results mathematically, but we shall explain the logic of each prediction. ${ }^{18}$ A brief explanation of each proposition will be given, and then some will be discussed in detail.

According to the first proposition, $\mathrm{P} 1$, a higher discount rate makes a plaintiff eager to settle, rather than postpone, resolution of the dispute until trial, so he adopts a more conciliatory strategy, and settlement is more likely. The discount rate refers to a litigant's time preference or the subjective urgency of settlement. For example, a divorcing spouse who is eager to remarry would pay a premium to resolve the dispute quickly, so his discount rate applied to the dispute is high.

According to proposition $\mathrm{P} 2$, an improvement in a litigant's prospects at trial will make trial less risky for him, so he will demand more in the negotiation process. If the litigants have a future interest in the trial, then the value of trial to one litigant can rise without the value of trial diminishing for his opponent. For instance, an insurance company places more value on a favorable precedent if it will apply to many of its future disputes. If one litigant's value of trial increases, without his opponent's worsening, then the first litigant's greater demand will make settlement less likely (P2).

The third proposition concerns the cost of bargaining, such as lawyer's fees and litigants' time. If a round of bargaining becomes more costly, then the players want to settle sooner in order to avoid protracted bargaining. They will adopt a more conciliatory strategy in order to settle sooner, so settlement is more likely (P3). Similarly, an increase in the transaction cost of a trial, such as expert-witness fees, makes the negotiators more eager to avoid a trial, so settlement is more likely (P4).

${ }^{18}$ The predictions are derived explicitly in Cooter \& Marks, supra note 4. 
Sometimes one of the litigants will enjoy special income as long as the dispute is unresolved. For example, if possession of a house is in dispute, one of the disputants will often enjoy the use of the house or the income from it while the dispute is pending. An increase in earnings per period while awaiting resolution of the dispute makes a litigant more willing to bargain down to the last minute before trial, thus increasing the probability of miscalculation and decreasing the probability of settlement (P5).

Spite is, by definition, the willingness of a litigant to reduce his payoff in order to reduce his opponent's payoff. An increase in spitefulness decreases the probability of settlement by making destruction of the surplus more acceptable to each player (P6). Risk aversion refers to the subjective attitudes of a person toward gambling. Less aversion to risk makes a player more inclined to gamble and demand a large share of the stakes, thus decreasing the probability of settlement (P7). If opponents are more familiar with each other, so that each player has more information about his opponent's likely strategy (smaller variance in strategies), then the miscalculations which cause a trial are less likely (P8), as explained in Part II.

Most of these predictions are consistent with those derived from the optimism model. Our aim is not to refute the optimism model but to extend its predictions by grounding them in a more fundamental account of bargaining. Our account is more fundamental because it describes the bargaining process, which is omitted from the optimism model. Since the optimism model does not describe the bargaining process, it offers no account of why bargaining takes time. In our model, bargaining consists of exchanging offers and counteroffers through a series of rounds of negotiation until a settlement is reached or the trial date arrives. An increase in the probability of a settlement in our model is equivalent to a decrease in the time required on average to reach a settlement. Thus we could relabel Table 1 and regard it as a table of predictions concerning speed of settlement rather than probability of settlement. This is an illustration of how to extend the predictions of the optimism model.

Including time in our model leads to a more detailed account of transaction costs. An increase in the cost of bargaining diminishes the likelihood that players will choose to enter negotiations. However, once players are committed to negotiating, an increase in the cost of bargaining speeds up the process of making concessions, as depicted in Figure 3. Concessions are speeded up because the parties try to settle sooner in order to avoid additional rounds of negotiation. Thus there are two opposing effects of an increase in the transaction cost of each round of negotiations: players are less willing to negotiate (negative negotiation effect), and more conciliatory in the event that they do negotiate (positive 


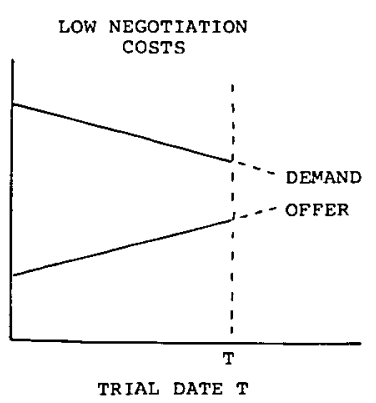

A

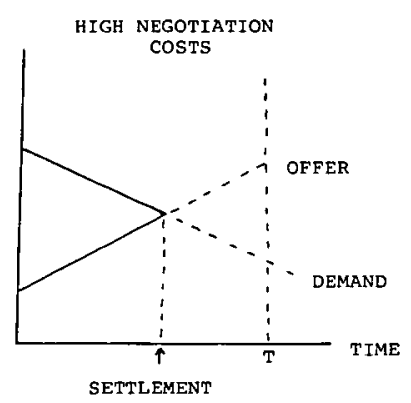

B

FIGURE 3

conciliation effect). An increase in the cost of a round of bargaining has a negative negotiation effect, which makes trial more likely, and a positive conciliation effect, which makes trial less likely.

The optimism model has no place for conciliation effects because it has no account of the bargaining process. Consequently, the optimism model takes notice only of the negotiation effect and predicts that higher transaction costs of negotiating will reduce the probability of settlement. A feature of our model which simplifies bargaining mathematically is that the parties negotiate with each other until a settlement is reached or trial begins. Our model does not allow the parties to save transaction costs by withdrawing from negotiations and awaiting trial. In our model there is a conciliation effect, but not a negotiation effect, from increasing the cost of a round of negotiations. Consequently, we predict that increasing the transaction cost of negotiating will increase the probability of settlement (P3).

We have explained why $\mathrm{P} 3$ contradicts the usual conclusion of the optimism model. It is possible to think of situations in which the conciliation effect will be stronger than the negotiation effect, so that predictions from our model will be right and predictions from the optimism model will be wrong. For example, institutions that require good faith bargaining as a prelude to trial eliminate the negotiation effect. If good faith bargaining is required, and the cost of a round of bargaining increases, then the parties will try to settle sooner, thus increasing the probability of reaching settlement before the trial date.

In the introduction we stated that our predictions would answer three perplexing questions: (1) Is settlement more likely when transaction costs are low? (2) Is settlement more likely when bargaining is risky? (3) Is settlement more likely when the cooperative surplus is large? We answered the first question by our proposition that settlement will be more 
likely when transaction costs of negotiating are high if conciliation effects dominate negotiation effects (P3). We answered the second question in Part II, where we explained that an increase in the variance of bargaining strategies makes settlement less likely (P8). Thus we have answered the first two questions, but not the third.

Our table of predictions does not refer explicitly to the surplus, but establishing that connection is simple. The surplus is the amount of the stakes that will be destroyed by disagreement. The surplus includes the transaction costs of a trial. If the amount destroyed by disagreement increases, with no change in the amount obtained by agreement (that is, no change in the stakes), then agreeing becomes more attractive. If agreeing becomes more attractive, then the bargainers will adopt softer strategies, and a trial will be less likely.

It is worthwhile to relate our table of predictions to repeat players. In our model, the players have rational expectations about the bargaining strategies which will be adopted by their opponents. These expectations are formed by a frequency distribution over litigants with the same observable traits. A player's current bargaining strategy will influence the expectations of future litigants. If a player has no future interest in litigation, then he has no incentive for influencing the expectations of future litigants. If a player litigates repeatedly, then he has an incentive for influencing the expectations of future litigants.

A player without an interest in future litigation chooses a strategy which balances a larger share of a possible settlement against a higher probability of trial. A player with a future interest must also take into account that a harder bargaining strategy today will cause his future opponents to adopt softer strategies. Consequently, our model predicts that a repeat player whose opponents are not repeat players will adopt a hard bargaining strategy. The situation is different if a repeat player's opponent is another repeat player. The usual prediction from game theory is that settlement will be more likely if both players repeat. ${ }^{19}$ This conclusion is confirmed by $\mathbf{P 8}$ in our table of predictions.

Insurance is an institution which substitutes repeat players for players with little future interest in litigation. Our theory predicts that, where insurance companies are involved in suits against individuals, the insurance companies will adopt hard bargaining strategies. However, if insurance companies are involved in suits against other insurance companies, then settlement will be likely.

19 For example, see Roy Radner, Monitoring Cooperative Agreements in a Repeated Principal-Agent Relationship (undated revision of 1979 paper, Working Paper, Bell Laboratories). 


\section{LEgAL INSTITUTIONS}

Propositions P1-P8 predict the signs on variables where the dependent variable is the probability of trial and the explanatory variables are potentially observable characteristics of the litigants. Thus we have produced a testable model of bargaining in the legal context. However, the predictions P1-P8 are not formulated in terms of legal institutions. The usefulness of our theory can be increased by bringing our abstract model and its predictions into contact with legal institutions.

\section{Externalities and Coase}

The first application of our model is to harmful externalities. The inefficiencies caused by externalities can be avoided by private bargaining, as observed by Coase. One interpretation of the Coase theorem holds that efficiency will be achieved in the presence of harmful externalities, regardless of the structure of liability law, provided that the transaction costs of bargaining are nil. ${ }^{20}$ If there are no impediments to bargains, then bargaining will continue until the gains from trade are exhausted. The gains from trade are exhausted when it is impossible to make one person better off without making someone else worse off (Pareto efficiency). Thus efficiency will be achieved by contracting around inefficient laws. According to this interpretation, the Coase theorem is an application of the proposition, "Bargaining games with zero transaction costs have efficient solutions." 21

The term "transaction costs" has a curious history in economics and law. Most theoretical terms eventually acquire a precise mathematical meaning, such as competition, demand, utility, public good, etc. "Transaction costs" has never been pinned down. Most writers take this term to include such costs as communicating and policing agreements. ${ }^{22}$ If we define transaction costs to mean the cost of communicating and policing agreements, then it is not true in our model that bargaining games with zero transaction costs reach efficient solutions. We predict the opposite: settlement is more likely if a round of negotiations is more costly (positive conciliation effect), as discussed in Part III.

The bargaining interpretation of the Coase theorem takes an optimistic

20 "[I]f one assumes rationality, no transaction costs, and no legal impediments to bargaining, all misallocations of resources will be fully cured in the market by bargains." Guido Calabresi, Transaction Costs, Resource Allocation and Liability Rules-A Comment, $11 \mathrm{~J}$. Law \& Econ. 67, 68 (1968).

${ }^{21}$ Donald H. Regan, The Problem of Social Cost Revisited, 15 J. Law \& Econ. 427 (1972).

22 "By transaction costs, $I$ have in mind costs like those of getting large numbers of people together to bargain, and costs of excluding freeloaders." Calabresi, supra note 20, at 68 n.5. 
view about the ability of people to resolve distributional disputes and cooperate. A pessimistic approach assumes that people cannot always solve the distribution problem, even if there are no costs to bargaining. According to this view, there is no guarantee that rationally self-interested players will agree about how to divide the stakes. Rationality requires the players to adopt strategies in which they risk destroying the surplus in order to gain a larger share of the stakes in the event of settlement. Rational players expect bargaining to break down in a certain proportion of cases, even if the cost of communicating and policing agreements is low.

The pessimistic view of private cooperation is articulated in Hobbes and is probably much older. ${ }^{23}$ It is based on the belief that people will exercise their worst threats against each other unless there is a third party to coerce both of them. For Hobbes, the third party is the prince or Leviathan-we would say dictatorial government.

Hobbes's pessimistic conception of private bargaining is familiar in criminal and constitutional law. There is no reason why the same conception cannot be applied to polluting a stream, breaching a contract, or causing an accident. This line of thought leads to the polar opposite of the Coase theorem, which could be called the Hobbes theorem: "Private bargaining to redistribute external costs will not achieve efficiency unless there is an institutional mechanism to dictate the terms of the contract for dividing the stakes." The Hobbes theorem suggests that the law should be structured to eliminate the most destructive acts. In the jargon of game theory, law should increase the value of the noncooperative solution by eliminating elements of the payoff matrix with low value.

It is not difficult to think of examples in which the optimistic and pessimistic approaches conflict. Suppose there is a small laundry which suffers from smoke emitted by a large factory. At issue is whether the laundry should be able to enjoin the factory. Since there are only two parties to the dispute, the cost of communicating and policing an agreement is small. The optimistic view holds that the outcome will be efficient whether or not the laundry can enjoin the factory. The pessimistic view holds that bargaining fails in some cases even when communication is costless, so it would be dangerous to permit a small laundry to enjoin a large factory.

Divorce provides another example. Research in progress by the authors shows that 15-20 percent of divorces involving children are resolved by trial. Our research also shows that the outcome of trial is easy to predict. It seems difficult to explain why two-party disputes, in which the trial

${ }^{23}$ Thomas Hobbes, Leviathan. 
outcome is predictable, would not be settled if transaction costs and optimism are the causes of trial, rather than strategic bargaining.

In the optimistic view, the need for government diminishes as bargaining costs diminish. In the pessimistic view, the need for government diminishes as the power of the parties to threaten each other diminishes, for instance, as competition increases. It would be interesting to pit these two views against each other in an examination of legal cases, in order to allocate the truth between them. This paper is not the place for such a comparison. ${ }^{24}$

\section{Reallocating Costs}

Now we turn to a new topic: How does a reallocation of the payoffs from trial affect the probability of settlement? One way to reallocate the payoffs from trial is to reallocate legal fees. Another way is to contract around the court's allocation of the stakes. We shall analyze legal institutions which reallocate the payoffs from trial by both methods.

One institution for reallocating the cost of trial is the so-called offer to compromise. In California, offers to compromise are called 998 offers because of the statutory section number authorizing them. ${ }^{25}$ Either party to a suit can make an offer to compromise, which typically is registered with the court. If the offer is rejected and a trial occurs, then the party who rejected the offer must pay the court costs of his opponent unless the judgment is more favorable than the offer. For example, if the plaintiff rejects an offer to settle for $\$ 10,000$ and wins a judgment of $\$ 8,000$, then the plaintiff pays the defendant's court costs. Court costs are a significant proportion of litigation expenses in cases involving expensive expert testimony.

The common belief that offers to compromise reduce the frequency with which suits end in trial is confirmed by our model. To see this point, let us consider the effect of this institution on the strategies of litigants. Suppose that the litigants have computed their optimal bargaining strategies without this institution. Assume that the exchange of offers goes to the wire without settlement. The final set of offers just before trial is optimal, that is, the loss which a litigant would suffer from a slightly more generous offer in the event of settlement is exactly offset by the expected gain due to the reduced probability of trial.

If the institution of offers to compromise is introduced, then the final offers will no longer be optimal. Offers to compromise in effect tax hard

\footnotetext{
24 See Robert Cooter, The Cost of Coase, 11 J. Legal Stud. 1 (1982).

${ }^{25}$ Steven Kirby \& Dale Nance, Costs, Attomey's Fees and Interest, California Civil Procedure during Trial (Calif. Continuing Education of the Bar, forthcoming).
} 
strategies and subsidize soft strategies; that is, a slightly more generous offer will be subsidized by one's opponent in the event of trial. Both players will want to revise their strategies to make more generous offers. Softer bargaining strategies imply fewer trials in equilibrium. ${ }^{26}$

Different legal systems have different rules for allocating the costs of litigation. A difference between American and British law is that in America the parties to a suit typically bear their own legal costs, whereas in Britain the loser pays the legal costs of both parties. ${ }^{27}$ We can use our model to predict the effect of this difference on the frequency of trial.

Think of a trial as a gamble. The expected value of the gamble is what a gambler believes the payoff to be on average. The expected value of trial is higher under the British rule for a litigant who is optimistic about winning the suit, and the expected value of trial is higher under the American rule for a pessimistic litigant. The risk of the gamble is the difference between the best and the worst possible payoffs. The risk is greater under the British rule than under the American.

When trial becomes more attractive, settlement becomes less likely (P2). Trial will be more attractive under the American rule than the British for pessimistic litigants, because the expected value is higher and the risk is less. Trial will be more attractive under the British rule for optimistic litigants who are risk neutral or only slightly risk averse, because the expected value is greater. Extremely risk-averse persons, whether optimistic or pessimistic, will prefer trial under the American rule because of its lower risk.

Are litigants typically optimistic or pessimistic? We have already discussed the tradition of thought which holds that trials occur because litigants are optimistic. If optimism is the cause of trials, and if litigants are not too risk averse, then the British rule will cause more suits to be tried. ${ }^{28}$

In the model developed in this paper, trial results from strategic behavior. Optimism is a secondary cause of trial. In our model, expectations are rational in the sense that litigants are neither overly optimistic nor overly

\footnotetext{
${ }^{26}$ It should be noted that these results are based on the assumption of equal marginal wealth effects and rational expectations as to trial outcomes. High optimism could lead to the opposite result. That is, if players are highly optimistic, then offers to compromise could lead to a higher probability of trial. See Cooter \& Marks, supra note 4.

27 The British and American systems are compared, using the optimism model of trial in Steven Shavell, Suit, Settlement, and Litigation: Theoretical Analysis under Alternative Methods of Allocating Legal Costs (1980) (unpublished paper). Shavell's paper builds on Economic Analysis, supra note 1, at 445-53.

${ }^{28}$ We advance this hypothesis tentatively because extreme risk aversion may cause more suits to be tried in the American system than in the British system, regardless of the optimism or pessimism of the litigants.
} 
pessimistic. ${ }^{29}$ If our model is correct, then we can predict that a larger proportion of suits will be tried under the American rule than under the British rule.

We have identified a test for choosing between the theory that trial results from optimism and the theory that trial results from strategic behavior. If the American rule causes more suits to end in trial than the British rule, then the facts favor the theory that trial results from strategic behavior. If the reverse is true, then the facts favor the theory that trial results from optimism. Of course, an econometric test of the facts would involve multiple variables, since there are many differences between actual legal systems besides the method for allocating legal costs. Actual econometric comparison between the American and British systems is difficult because the social and legal environments are so different.

\section{Conclusion}

In our model of bargaining in the shadow of the law, a dispute arises over the division of an asset or liability. If the parties can agree on a division of the stakes, then the cost of settling the dispute is low. If the parties cannot agree, then a costly trial will be held which destroys part of the stakes and distributes the remainder. A rational bargainer will trade off the gain from demanding more against the higher risk of a trial. The optimal strategy involves a positive risk of trial. In equilibrium expectations are rational in the sense that no player is surprised by the frequency with which trials occur. Biased expectations, however, are easily incorporated into the model.

It is a feature of our model that a trial can occur even though neither party is optimistic about its outcome. Trials can occur in such circumstances because each party is uncertain about how much his opponent will concede in the course of negotiations. Uncertainty persists in equilibrium because the players have unobservable attributes which influence their bargaining strategies. In equilibrium, opponents know the distribution of strategies, given the observable traits, but not the strategy of a particular opponent. The equilibrium concept appropriate to such a game is a Bayesian Nash equilibrium.

In bargaining, changes in tangible variables have psychological effects. The psychological effects operate through the expectations of the players. We show that the direct effect on a player's strategy dominates the indi-

${ }^{29}$ The theory that trial results from optimism requires at least one of the parties to be overly optimistic, because the objectively expected payoffs from trial cannot add up to more than the stakes. If players are overly optimistic in this sense, then they are probably optimistic in the sense that both assign a high probability to winning at trial. 
rect effects that operate through expectations in the usual case. We can predict changes in the probability of settlement caused by changes in tangible variables by using economic theory alone, provided that direct effects dominate indirect effects.

Our model has some implications for the discussion of transaction costs and the Coase theorem. In our model it is not true that a settlement will occur if the cost of sending messages and policing agreements is nil. Furthermore, it is not true that reducing the cost of sending messages increases the probability of an agreement. The Coase theorem is not true in the limit as transaction costs go to zero in our model. The obstacle to agreement is the strategic nature of bargaining, not the cost of communicating. Consequently, it is desirable for the law to eliminate the worst threats which the parties can make against each other, even when there are small numbers of bargainers (Hobbes theorem).

Our model also has implications for the analysis of institutions for reallocating the payoffs from trial. The institution of offers to compromise creates a subsidy for generous offers and a tax on high demands, thereby increasing the frequency of settlement. If each party bears his own legal fees (American rule), then trial is less risky than it would be if the loser paid the legal fees of both parties. If the expectations of litigants are rational, rather than optimistic, then more trials will occur when trials are less risky (American rule). If the expectations of litigants are optimistic, then more trials will occur when the loser has to pay the winner's legal fees (British rule), provided that litigants are not too risk averse.

\section{MATHEMATICAL APPENDIX}

The arguments in the text are illustrated for mathematical readers by developing our divorce example quantitatively. A lengthy development of the mathematics, including formal proofs, is in a companion paper on file with this Journal.

\section{Individual Optimization and the Objective Distributions}

Suppose that divorcing spouses must divide the value of a house worth $\$ 100,000$. For convenience, let us take the units of measurement to be $\$ 100,000$ so that the house is worth one unit. To begin the example, let us assume that each player makes a demand, denoted $b$. If the demands add to less than one, then each player receives his or her demand. Otherwise there is a trial which has an expected utility of $T^{w}$ for the wife and $T^{h}$ for the husband. We assume that there is a set of observable attributes, $w$, and unobservable attributes, $u^{w}$ and $u^{h}$, for the wife and husband, respectively. Each player has an expected utility function written: $V^{i}=\hat{R}\left(1-b ; \hat{\mu}^{j}, \hat{\sigma}^{j}\right) U\left(b, u^{i}, w\right)+\left[1-\hat{R}\left(1-b, \hat{\mu}^{j}, \hat{\sigma}^{j}\right)\right] T^{i}$, where $\hat{R}$ is a cumulative distribution function which represents what player $i$ feels are player $j$ 's 
likely demands. We assume that $\hat{R}^{j}$ is completely specified by the mean-variance vector $\left(\hat{\mu}^{j}, \hat{\sigma}^{j}\right)$, where ${ }^{\wedge}$ indicates a subjective variable.

Each player's choice of strategy is found by maximizing $V^{i}$. The solution is the player's optimal demand $b$, which is a function of the parameters of $V^{i}$, namely, $u^{i}$, $w, \hat{\mu}^{j}$, and $\hat{\sigma}^{j}$. Different players with the same observable characteristics $w$, but different unobservable characteristics $u^{i}$, will have different optimal demands. The objective distribution of the optimal demands is denoted $\vec{R}^{i}$ for $i=w$ or $h$, with mean and variance $\left(\vec{\mu}^{i}, \vec{\sigma}\right)$, where the overbar indicates an objective variable. Given the distribution of unobservable attributes in the population, the mean and variance of the objective distributions are functions of the observable attributes and the subjective moments. These functions are denoted: $\bar{\mu}^{i}=\bar{\mu}^{i}\left(w, \hat{\mu}^{j}, \hat{\sigma}^{j}\right), \bar{\sigma}^{i}=$ $\bar{\sigma}^{i}\left(w, \hat{\mu}^{j}, \hat{\sigma}^{j}\right)$.

\section{Expectations, Equilibria, ANd Direct EfFEcts}

We define equilibrium $\left(\mu^{*}, \sigma^{*}\right)$ as a condition in which subjective means and variances equal objective means and variances: $\left(\mu^{*}, \sigma^{*}\right)=(\hat{\mu}, \hat{\sigma})=(\bar{\mu}, \bar{\sigma})$, or $\mu^{i^{*}}=$ $\bar{\mu}^{i}\left(w, \mu^{j^{*}}, \sigma^{j^{*}}\right), \sigma^{i^{*}}=\bar{\sigma}^{i}\left(w, \mu^{j^{*}}, \sigma^{j^{*}}\right)$. The existence of an equilibrium can be proved by using a fixed-point theorem.

The total effect of a change in observable variables $w$ is the change in the equilibrium moments: $\left(\partial \mu^{i *} / \partial w\right)=\left(\partial \bar{\mu}^{i} / \partial w\right)+\left(\partial \bar{\mu}^{i} / \partial \hat{\mu}^{j}\right)\left(\partial \mu^{j *} / \partial w\right)+\left(\partial \bar{\mu}^{i} / \partial \hat{\sigma}^{j}\right)\left(\partial \sigma^{j^{*}} / \partial w\right)$, $\left(\partial \sigma^{i *} / \partial w\right)=\left(\partial \bar{\sigma}^{i} / \partial w\right)+\left(\partial \bar{\sigma}^{i} / \partial \hat{\mu}^{j}\right)\left(\partial \mu^{j *} / \partial w\right)+\left(\partial \bar{\sigma}^{i} / \partial \hat{\sigma}^{j}\right)\left(\partial \mu^{j *} / \partial w\right)$. The direct effect of a change in the observable variable $w$ is the change in the distribution of strategies which would occur if there were no change in subjective expectations. It is the first term to the right of the equality sign in each of the preceding two equations. The indirect effects are the changes due to the changed expectations alone. They are represented by the second two terms to the right of the equality. The direct effects are said to dominate the indirect effects if the sign of the total effect on the probability of settlement is the same as the sign of the direct effect.

\section{The Direct Effect and the Probability of Settlement}

It is possible to show that a change in an observable variable which influences the mean strategies $\mu$, with no change in variances $\sigma$, will have a total effect whose sign is the same as the direct effect. For illustration, assume that there is a change in $w_{i}$ which (i) has a direct effect only upon the husband, $(\partial \bar{\mu} w / \partial w)=0$, and (ii) does not change the variances of $\bar{R}$ or $\hat{R}$ in equilibrium, $0=\left(d \sigma^{*} / d w_{i}\right)$. The total effect upon husband's and wife's strategies can be written $\left(d \mu^{h *} / d w_{i}\right)=$ $\left(\partial \bar{\mu}^{h} / \partial w_{i}\right)+\left(\partial \bar{\mu}^{h} / \partial \hat{\mu}^{w}\right)\left(d \mu^{w^{*}} / d w_{i}\right)$, and $\left(d \mu^{w^{*}} / d w_{i}\right)=\left(\partial \bar{\mu}^{w} / \partial \hat{\mu}^{h}\right)\left(d \mu^{h *} / d w_{i}\right)$. Solving simultaneously yields

$$
\left(d \mu^{h^{*}} / d w_{i}\right)=\frac{\left[\left(\partial \bar{\mu}^{h} / \partial w_{i}\right)\right.}{\left.1-\left(\partial \bar{\mu}^{h} / \partial \hat{\mu}^{w}\right)\left(\partial \bar{\mu}^{w} / \partial \hat{\mu}^{h}\right)\right]},
$$

and

$$
\left(d \mu^{w^{*} / d w_{i}}\right)=\frac{\left(\partial \bar{\mu}^{h} / \partial w_{i}\right)\left(\partial \bar{\mu}^{w / \partial} \hat{\mu}^{h}\right)}{1-\left(\partial \bar{\mu}^{h} / \partial \hat{\mu}^{w}\right)\left(\partial \bar{\mu}^{w} / \partial \hat{\mu}^{h}\right)}
$$


Thus we have

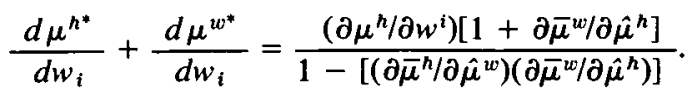

For stability, the denominator must be nonnegative. Furthermore, it can be shown that $\left(\partial \bar{\mu}^{w / \partial} \hat{\mu}^{h}\right)>-1$. Thus we have

$$
\begin{gathered}
\text { total effect } \\
\operatorname{sign}\left(\frac{d \mu^{h^{*}}}{d w_{i}}+\frac{d \mu^{w^{*}}}{d w_{i}}\right)=\operatorname{sign}\left(\frac{\partial \mu^{h}}{\partial w_{i}}\right) .
\end{gathered}
$$

\section{A Priori Estimation of the Direct Effect}

If the left side of the preceding equality (total effect) is positive, then we predict that trial is more likely. This is because the means of the demands are, on average, higher, with no change in variance, by construction of our example. The sign on the right side of the equation (direct effect) is usually easy to predict a priori. Thus we can make a priori predictions of changes in the frequency of trial when direct effects dominate indirect effects.

For example, consider the husband's optimization problem. He must maximize $V^{h}$ over $b^{h}$. Let $b^{h^{*}}$ be the maximum at equilibrium, so we can write: $b^{h^{*}}=\phi^{h}\left(u^{h}\right.$, $\left.w, \hat{\mu}^{*}, \hat{\sigma}^{*}\right)$. The direct effect of a change in $w$ is the change in $b^{h}$ holding expectations $(\hat{\mu}, \hat{\sigma})$ constant, $\left(\partial \phi^{h} / \partial w\right)$, which is usually easy to compute. For example, we can prove that persons with more debts, ceteris paribus, bargain easier. The direct effect for individuals is the same as for the mean of the distribution:

$$
\operatorname{sign}\left(\frac{\partial \phi^{h}}{\partial w_{i}}\right)=\operatorname{sign}\left(\frac{\partial \mu^{h}}{\partial w_{i}}\right)
$$

\section{Direct EFFect Dominance: InTUITION}

Heuristically, we can say that a direct effect which weakens one player's demand will increase the probability of settlement. That is, the second player will advance by less than the first player retreats. An intuitive explanation can be seen by noting Figure 4 . Let us consider the wife's optimization decision. Let us assume that she is risk neutral, for simplicity, and has the following objective function: $\hat{R}\left(1-b^{w}\right) b^{w}+\left[1-\hat{R}\left(1-b^{w}\right)\right] T^{w}$, where $R$ is the probability of settlement (no trial), that is, the probability that the husband will demand less than $1-b^{w}$. The first-order condition for an internal solution is: $-\left(b^{w}-T^{w}\right) d \hat{R}=\hat{R} d b^{w}$. The left represents losses from a unit increase in the wife's demand and the right represents gains.

For concreteness, suppose that the mean of $\hat{R}^{h}$ is $\hat{\mu}^{h}=1 / 2$ and the wife's optimal demand is $b^{u^{*}}$. Now let the husband's objective situation indicate a shift in the mean of his expected demand to $\hat{\mu}^{h}=1 / 4$, with no change in $\hat{\sigma}^{h}$. If the wife's optimal demand responds by increasing less than one-fourth, then settlement will be more likely.

It is easy to show that the wife's demand will increase by less than one-fourth. The proof is by contradiction. Assume that the wife's demand increases by exactly one-fourth. At this new value of $b^{w}$, the probability of settlement $\hat{R}$ and the 


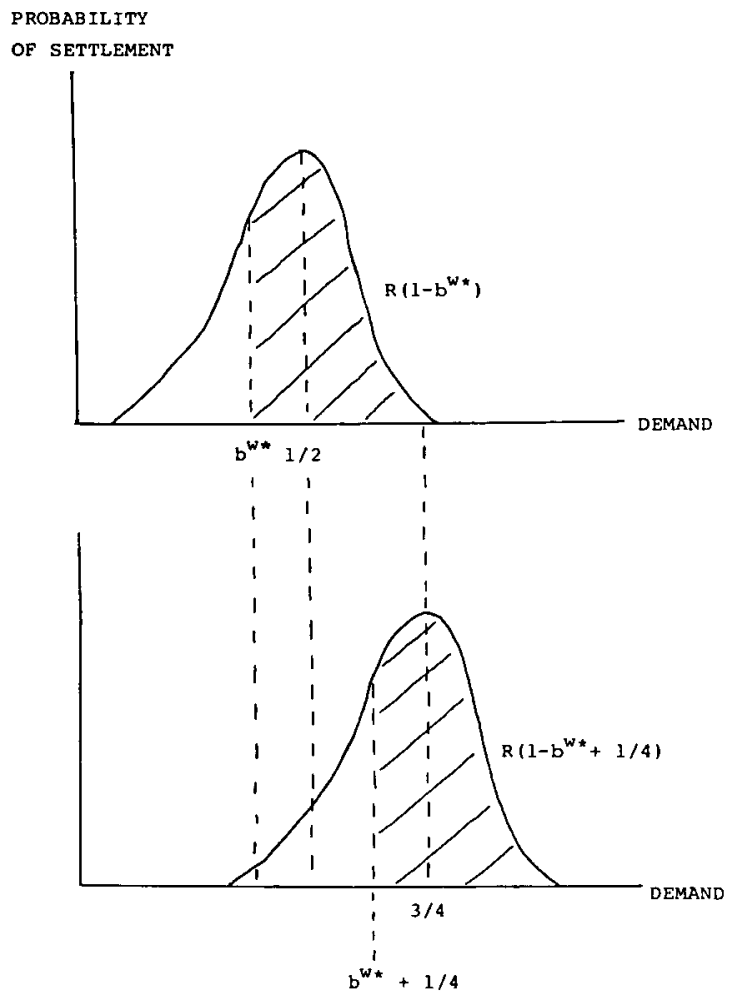

Figure 4

marginal probability of settlement $d \hat{R} / d b^{w}$ are unchanged, as depicted in Figure 4. However, the amount at risk in the event of trial, $b^{w}-T^{w}$, has increased by one-fourth. Thus the first-order condition stated above cannot be satisfied, which proves that increasing $b^{w}$ by one-fourth is not optimal. Since the derivative of the objective function is negative at this point, the new optimum is to be found at a smaller value of $b^{w}$. Thus the wife's optimal demand increases by less than onefourth when the husband's demand decreases by one-fourth, and settlement is more likely.

\section{Reduction of Bargaining to ONe-Shot Game}

Our quantitative example is a "one-shot" game, by which we mean that the husband and wife make one demand each. Real bargaining involves a sequence of offers and counteroffers, but analysis requires reducing the sequence to a one-shot game. The generalization of the concept of a higher demand is the concept of a harder strategy. We reduce complex strategies to a single dimension by ranking them according to hardness. It is worth describing how this reduction is accomplished in mathematical model. 
A bargainer forms a plan for making offers in each round of negotiations. $\mathrm{He}$ will probably want to revise the plan according to the way bargaining goes in the early rounds. We can model this process by imagining a superrational bargainer who constructs a complete set of contingency plans before the first round of negotiations. The offer $x_{i}$ at any period $i$ will be affected by the entire history of prior offers and counteroffers, denoted $x_{i}$. The strategy of this superrational player is a sequence of contingent offers, or a sequence of offer functions: $(s)=\left(x_{1}, x_{2}\right.$, $\left.\ldots, x_{T}\right)$, where $x_{i}=f\left(x_{i}\right)$ all $i \leqslant T$.

It will usually be possible to rank strategies according to how hard or tough they are. In our notation, one strategy is harder than another if the demands under the first strategy are at least as great as the demands under the second strategy for every possible contingency: $(\bar{s})$ harder than $(\bar{s})<=>\left[\left(\bar{x}_{1}, \bar{x}_{2}, \ldots, \bar{x}_{T}\right) \geqslant\left(\bar{x}_{1}, \overline{\bar{x}}_{2}\right.\right.$, $\left.\left.\ldots, \overline{\bar{x}}_{T}\right)\right]$.

The hardness relation partially ranks strategies. We assume that this ranking is rich enough so that the players will optimize by choosing the best strategy from a subset which can be ranked by hardness. Under this assumption, we can completely describe each player's strategy by characterizing how hard it is. The game is reduced to one-shot bargaining by imagining that each player picks his strategy before the first round of negotiations. Trial occurs if the pair of strategies pursued by the players are too hard, which is the generalization of the assumption that trial occurs if the sum of the demands exceeds the surplus. 
HeinOnline -- 11 J. Legal Stud. 2521982 